\title{
Pedrolane, a Polycyclic Diterpene Scaffold Containing a Bicyclo[2.2.1] heptane System, from Euphorbia pedroi
}

\author{
Ricardo J. Ferreira, Gabriella Spengler, Andreas Orthaber, Daniel J. V. A. dos Santos, \\ and Maria-José U. Ferreira*
}

Cite This: Org. Lett. 2021, 23, 274-278

Read Online

\section{ACCESS | Llll Metrics \& More | 回 Article Recommendations | S1 Supporting Information}

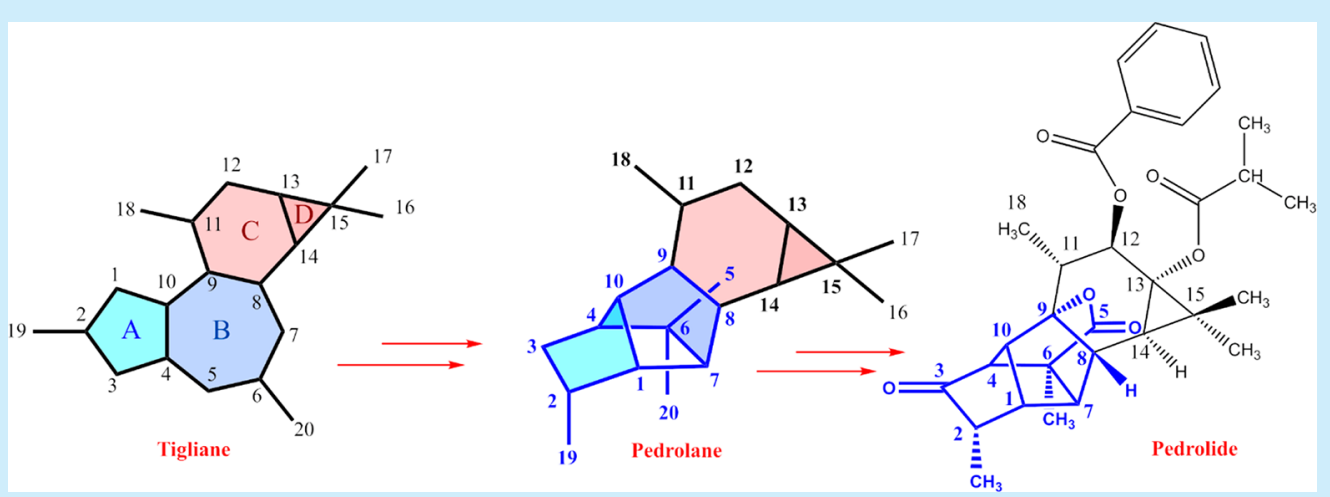

ABSTRACT: Pedrolide (1), a diterpenoid with an unprecedented carbon skeleton, pedrolane, containing a bicycle[2.2.1]heptane system, is reported. This structural feature is hypothesized to involve an intramolecular cyclization, via Michael addition, and a ring contraction, via 1,2-alkyl shift or a Pinacol rearrangement of rings A and B, from a tigliane-type 5/7/6/3-tetracyclic ring precursor. The structure of $\mathbf{1}$ was established using spectroscopic techniques, single-crystal X-ray diffraction, and $a b$ initio calculations. Pedrolide reversed multidrug resistance mediated by P-glycoprotein.

$\mathrm{T}$ he genus Euphorbia (Euphorbiaceae) is a key source of isoprenoids with unique structural diversity and remarkable biological activities. Most particularly, polyoxygenated macrocyclic jatrophane and lathyrane-type diterpenes and the biogenetically related polycyclic diterpenes, bearing tigliane, ingenane, and daphnane scaffolds, generally found as aliphatic and aromatic acyl derivatives, are considered important groups of compounds due to their multidrug-resistance reversal (MDR), cytotoxic, antitumor, antiviral, and anti-inflammatory activities.

Among these diterpenes, exclusively found in Euphorbiaceae and Thymelaeaceae families, the polycylic diterpene tigilanol tiglate, for treating solid tumors, ${ }^{2}$ and the daphnane-type diterpene resiniferatoxin, a strong nonopioid analgesic able to provide pain relief in patients with advanced cancer, ${ }^{3}$ are currently in clinical trials and represent two examples of the therapeutic potential of diterpenes from Euphorbia species. Tiglianes are characterized by a 5/7/6/3-tetracyclic ring system $(\mathrm{A} / \mathrm{B} / \mathrm{C} / \mathrm{D})$, with the fusion of rings $\mathrm{A}-\mathrm{B}$ usually trans, although the cis fusion of rings $\mathrm{A}-\mathrm{B}$ is increasingly being reported. ${ }^{1,4,5}$ Unvaryingly, the fusion of rings $\mathrm{B}-\mathrm{C}$ is always trans and of $\mathrm{C}-\mathrm{D}$ rings cis. $\mathrm{A}$ variable oxidation pattern, regarding the position of the double bonds and acylation pattern of oxygen functions, render them an unusual structural chemical diversity. Tiglianes are also characterized by the presence of an $\alpha, \beta$-unsaturated carbonyl system at ring $\mathrm{A}$, which is reported to be responsible for most of the activities described for this class of compounds, including proinflammatory, cocarcinogenic, tumorigenic, anticancer and antiviral activities. ${ }^{1,6}$

In our search for effective MDR reversers, ${ }^{7-12}$ the phytochemical study of Euphorbia pedroi Molero and Rovira, an endemic plant of the western sea cliffs in Portugal, was performed. $^{7}$ Herein a novel noncytotoxic tigliane-type diterpenoid was isolated from the methanol extract, with a previously unreported skeleton, which was evaluated for its ability to inhibit P-glycoprotein (P-gp/ABCB1).

Compound 1, named pedrolide, was isolated as white needles with $[\alpha]_{\mathrm{D}}^{20}+75.4^{\circ}\left(c \quad 0.1, \mathrm{CHCl}_{3}\right)$. While the IR spectrum provided evidence for the carbonyl function (1750 and $\left.1701 \mathrm{~cm}^{-1}\right)$, the low-resolution molecular ESI-MS spectrum revealed the presence of a protonated molecular

Received: November 2, 2020

Published: December 29, 2020 
ion at $m / z 521[\mathrm{M}+\mathrm{H}]^{+}$. From the ESI-HRMS spectrum, the identification of a potassium adduct ion at $\mathrm{m} / z 559.2096[\mathrm{M}+$ $\mathrm{K}]^{+}$allowed us to infer a molecular formula of $\mathrm{C}_{31} \mathrm{H}_{36} \mathrm{O}_{7}$ (Calcd for $\mathrm{C}_{31} \mathrm{H}_{36} \mathrm{O}_{7} \mathrm{~K}, 559.2093$ ), along with a degree of unsaturation of 14 .

The ${ }^{1} \mathrm{H}$ NMR spectrum (Table 1) showed proton resonances corresponding to seven methyl groups, three

Table 1. ${ }^{1} \mathrm{H}$ and ${ }^{13} \mathrm{C}$ NMR Spectra for Pedrolide (1) $\left(\mathrm{CDCl}_{3}, 300\right.$ and $75 \mathrm{MHz}$, Respectively)

\begin{tabular}{|c|c|c|}
\hline position & $\delta_{\mathrm{C}}$ & $\delta_{\mathrm{H}}($ mult, $J$ in $\mathrm{Hz})$ \\
\hline 1 & 55.6 & $2.63(\mathrm{~m})$ \\
\hline 2 & 45.0 & $2.39(\mathrm{qd}, 7.2,4.7)$ \\
\hline 3 & 212.2 & \\
\hline 4 & 63.1 & $2.61($ br d, 2.1) \\
\hline 5 & 176.8 & \\
\hline 6 & 45.6 & \\
\hline 7 & 46.7 & 2.44 (br s) \\
\hline 8 & 51.0 & $1.75($ br d, 5.5$)$ \\
\hline 9 & 88.5 & \\
\hline 10 & 50.1 & $3.03(\mathrm{dd}, 4.5,2.1)$ \\
\hline 11 & 43.4 & $1.80(\mathrm{dq}, 8.2,7.0)$ \\
\hline 12 & 80.1 & $5.95(\mathrm{~d}, 8.2)$ \\
\hline 13 & 66.4 & \\
\hline 14 & 28.2 & $0.96(\mathrm{~d}, 5.5)$ \\
\hline 15 & 30.3 & \\
\hline 16 & 23.2 & $1.12(\mathrm{~s})$ \\
\hline 17 & 18.0 & $1.45(\mathrm{~s})$ \\
\hline 18 & 13.8 & $1.18(\mathrm{~d}, 7.0)$ \\
\hline 19 & 12.4 & $1.25(\mathrm{~d}, 7.2)$ \\
\hline 20 & 17.4 & $1.25(\mathrm{~s})$ \\
\hline $1^{\prime}$ & 166.3 & \\
\hline $2^{\prime}$ & 130.9 & \\
\hline $3^{\prime}$ & 129.8 & $8.02(\mathrm{dd}, 7.2,1.4)$ \\
\hline $4^{\prime}$ & 128.5 & $7.44(\mathrm{dd}, 7.2,1.4)$ \\
\hline $5^{\prime}$ & 132.8 & $7.55(\mathrm{dd}, 7.2,1.4)$ \\
\hline $1^{\prime \prime}$ & 177.3 & \\
\hline $2^{\prime \prime}$ & 33.8 & $2.54(h, 7.0)$ \\
\hline $3^{\prime \prime}$ & 19.1 & $1.12(\mathrm{~d}, 7.0)$ \\
\hline $4^{\prime \prime}$ & 18.9 & $1.10(\mathrm{~d}, 7.0)$ \\
\hline
\end{tabular}

tertiary, as singlets, at $\delta_{\mathrm{H}} 1.12,1.25$, and 1.45 and four doublets of secondary methyl groups at $\delta_{\mathrm{H}} 1.10(J=7.0 \mathrm{~Hz})$, $1.12(J=7.0 \mathrm{~Hz}), 1.18(J=7.0 \mathrm{~Hz})$, and $1.25(J=7.2 \mathrm{~Hz})$ and a downfield signal of an oxymethine at $\delta_{\mathrm{H}} 5.95(1 \mathrm{H}, \mathrm{d}, J=8.2$ $\mathrm{Hz})$. Additionally, a multiplet at $\delta_{\mathrm{H}} 2.54(h, J=7.0 \mathrm{~Hz})$ in the aliphatic region indicated the presence of an isobutyryl group. Moreover, resonances corresponding to five aromatic protons $\left(\delta_{\mathrm{H}} 7.44,7.55\right.$, and 8.02$)$ were also observed, suggesting the presence of a benzoyl moiety. Both acyl groups were substantiated by the ${ }^{13} \mathrm{C}$ NMR data (isobutyryl, carbonyl at $\delta_{\mathrm{C}} 177.3$ and two methyls and one methine in the aliphatic region; benzoyl, carbonyl at $\delta_{\mathrm{C}} 166.3$ and six aromatic carbons).

In addition to the signals of the isobutyryl and benzoyl esters, the remaining signals in the ${ }^{13} \mathrm{C}$ NMR spectrum, along with the DEPT experiment, revealed the presence of twenty carbons, namely, five methyl groups, nine methines (one oxygenated, at $\left.\delta_{\mathrm{C}} 80.1\right)$, and six quaternary carbons, including two carbonyl (ketone at $\delta_{\mathrm{C}} 212.2$ and one acyl function at $\delta_{\mathrm{C}}$ 176.8) and two oxygenated carbons $\left(\delta_{\mathrm{C}} 66.4\right.$ and 88.5). The above structural features pointed to a diterpene scaffold for $\mathbf{1}$.
Detailed analysis of the two-dimensional NMR experiments $\left({ }^{1} \mathrm{H}-{ }^{1} \mathrm{H}\right.$ COSY, HMQC, HMBC, and NOESY) allowed us to elucidate the relevant structural details of $\mathbf{1}$, further assign proton and carbon signals, and locate the functional groups (Figure 1).

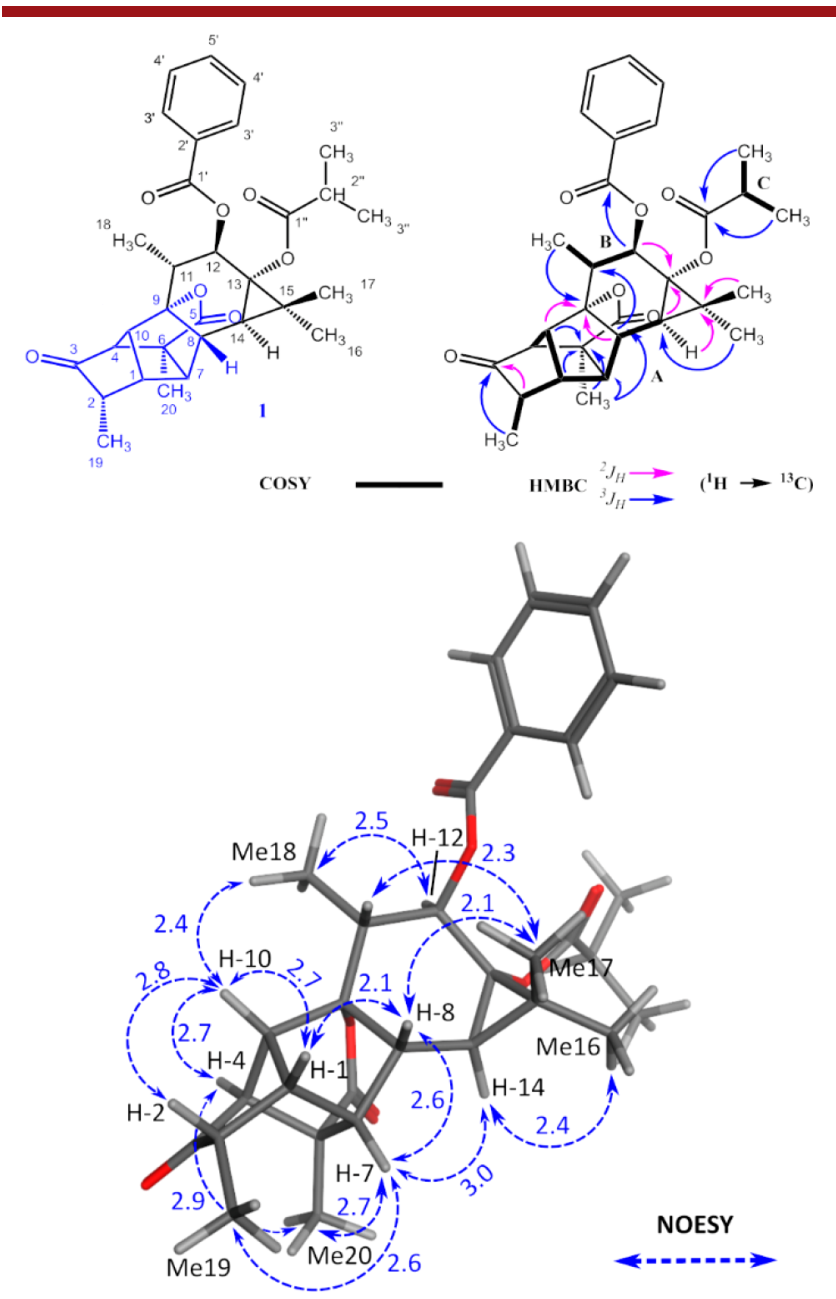

Figure 1. Structure and key COSY, HMBC, and NOESY correlations for pedrolide (1). The new structural features of compound (1) are depicted in blue. Distances between ${ }^{1} \mathrm{H}$ atom pairs, in angstroms, are depicted above the corresponding NOE correlation.

The ${ }^{1} \mathrm{H}-{ }^{1} \mathrm{H}$ COSY and HMQC spectra indicated three spin systems (A-C, Figure 1) connected by long-range heteronuclear correlations, found in the HMBC spectrum. A HMBC ${ }^{2} J_{\mathrm{C}-\mathrm{H}}$ correlation between $\mathrm{H}-10$ and $\mathrm{C}-9$, and a ${ }^{3} J_{\mathrm{C}-\mathrm{H}}$ correlation between $\mathrm{Me}-18$ and $\mathrm{C}-9$ connected the spin system A to B. Following, ${ }^{3} J_{\mathrm{C}-\mathrm{H}}$ correlations between $\mathrm{H}-7 / \mathrm{Me}-20, \mathrm{H}-$ 1/C-6, and H-10/C-6 located C-6 as bridging C-4 and C-7. In turn, correlations between $\mathrm{H}-12 / \mathrm{C}-13, \mathrm{H}-14 / \mathrm{C}-13 / \mathrm{C} 15$, Me16/C-13/C-14/C-15, and Me-17/C-13/C-15 connected spin system $\mathrm{B}$ to the cyclopropane ring. Concerning the position of the functional groups, the correlations found between $\mathrm{Me}-19$ and $\mathrm{C}-2 / \mathrm{C}-3$ and $\mathrm{H}-2 / \mathrm{C}-3$ located the ketone group at $\mathrm{C}-3$ $\left(\delta_{\mathrm{C}} 212.2\right)$. The lactone $\left(\delta_{\mathrm{C}} 176.8\right)$, between C-6 ( $\left.\delta_{\mathrm{C}} 45.6\right)$ and C-9 $\left(\delta_{\mathrm{C}} 88.5\right)$, was substantiated by the ${ }^{2} J_{\mathrm{C}-\mathrm{H}}$ correlations of Me-20 with C-6 $\left(\delta_{\mathrm{C}} 45.6\right)$ and ${ }^{3} J_{\mathrm{C}-\mathrm{H}}$ correlations of Me-20 with C-5 $\left(\delta_{\mathrm{C}} 176.8\right)$ and C-7 $\left(\delta_{\mathrm{C}} 46.7\right)$. The benzoate ester was placed at C-12 based on a ${ }^{3} \mathrm{~J}_{\mathrm{C}-\mathrm{H}}$ correlation between $\mathrm{H}-12$ $\left(\delta_{\mathrm{H}} 5.95\right)$ and the carbonyl carbon at $\delta_{\mathrm{C}} 166.3$. The absence of 
HMBC correlations involving the carbonyl at $\delta_{\mathrm{C}} 179.6$ of the isobutyrate ester function located it at C-13 $\left(\delta_{\mathrm{C}} 66.4\right) .{ }^{13,14}$

The above data provided evidence for the presence of some structural features, namely, ring $\mathrm{C}$ and the cyclopropane ring $\mathrm{D}$, of the tigliane scaffold in the structure of $\mathbf{1}$. However, other typical elements as the enone at ring $\mathrm{A}$ and a double bond at ring $\mathrm{B}$ (usually at C-5 or C-6) were absent. In fact, a detailed analysis of the ${ }^{1} \mathrm{H}-{ }^{1} \mathrm{H}$ COSY data and HMBC correlations observed for $\mathrm{H}-1, \mathrm{H}-4, \mathrm{H}-7, \mathrm{H}-8$, and $\mathrm{H}-10$ indicated the occurrence of a rearrangement involving this particular region of the molecule, which was assigned as a bicyclo[2.2.1] heptane feature.

To substantiate the type of rearrangement that occurred in $\mathbf{1}$, single crystal diffraction data (CCDC 1990457) of 1 was obtained (Figure 2). It allowed us to confirm that pedrolide

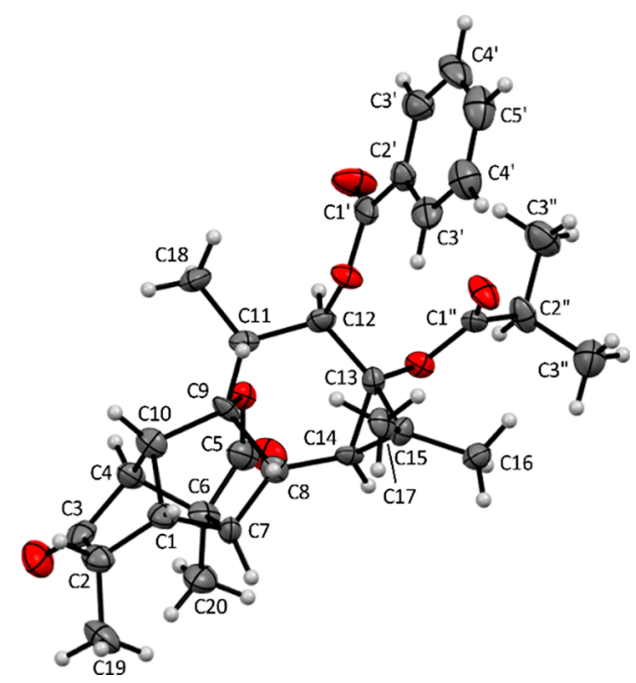

Figure 2. Single-crystal X-ray structure of $\mathbf{1 .}$

(1) was, in fact, a new compound with an unprecedented carbon skeleton, herein named pedrolane. However, and due to the weakly diffracting nature of the crystals, no information could be retrieved regarding the absolute configuration of $\mathbf{1}$.

The relative stereochemistry of $\mathbf{1}$ was thus assigned through both a NOESY experiment and an ab initio energy minimization. After importing the heavy atoms' spatial coordinates, obtained from the crystallographic structure into MOE, we performed two rounds of energy minimization to confirm the orientation of the hydrogen atoms (Supporting Information, Figure S20). Afterward, we cross-referenced the obtained spatial distances (Figure 1) with the 2D NOESY data. Accordingly, NOE cross peaks between H-14/Me-16, H-14/ $\mathrm{H}-7, \mathrm{H}-7 / \mathrm{Me}-20, \mathrm{H}-7 / \mathrm{Me}-19$, and $\mathrm{Me}-20 / \mathrm{H}-4$ showed that these protons are on the same side of the molecule. In turn, NOE correlations between $\mathrm{H}-11 / \mathrm{Me}-17, \mathrm{Me}-17 / \mathrm{H}-8, \mathrm{H}-8 / \mathrm{H}-$ 1 (very strong), $\mathrm{H}-1 / \mathrm{H}-2, \mathrm{H}-1 / \mathrm{H}-10$, and $\mathrm{H}-10 / \mathrm{H}-2$, indicated that these protons are on the opposite side of the molecule. Moreover, the configuration at the stereocenters $\mathrm{C}-11$ and $\mathrm{C}$ 12 were corroborated by NOE correlations between Me-18 and $\mathrm{H}-12$.

Thus, from the 2D NOESY data we obtained a relative configuration that was further used as input to calculate the specific rotation via an $a b$ initio approach $^{15}$ (Supporting Information, Computational Methodology section). We calculated the specific rotation of both epimers $4 R$ and $4 S$ for comparison purposes. Herein, the calculated $[\alpha]_{\mathrm{D}}$ values were $+84.0^{\circ}$ and $-80.9^{\circ}$ for epimers $4 S$ and $4 R$, respectively. Therefore, and due to the very good agreement of epimer $4 S$ with the experimentally determined specific rotation $\left(+75.4^{\circ}\right)$, the absolute configuration of pedrolide $(\mathbf{1})$ is proposed to be $1 S, 2 S, 4 S, 6 S, 7 R, 8 S, 9 R, 10 R, 11 R, 12 R, 13 S, 14 R$.

A hypothetical biosynthetic pathway for the carbon scaffold of compound $\mathbf{1}$ is proposed (Scheme 1) starting from a

Scheme 1. Hypothetical Biogenetic Pathway

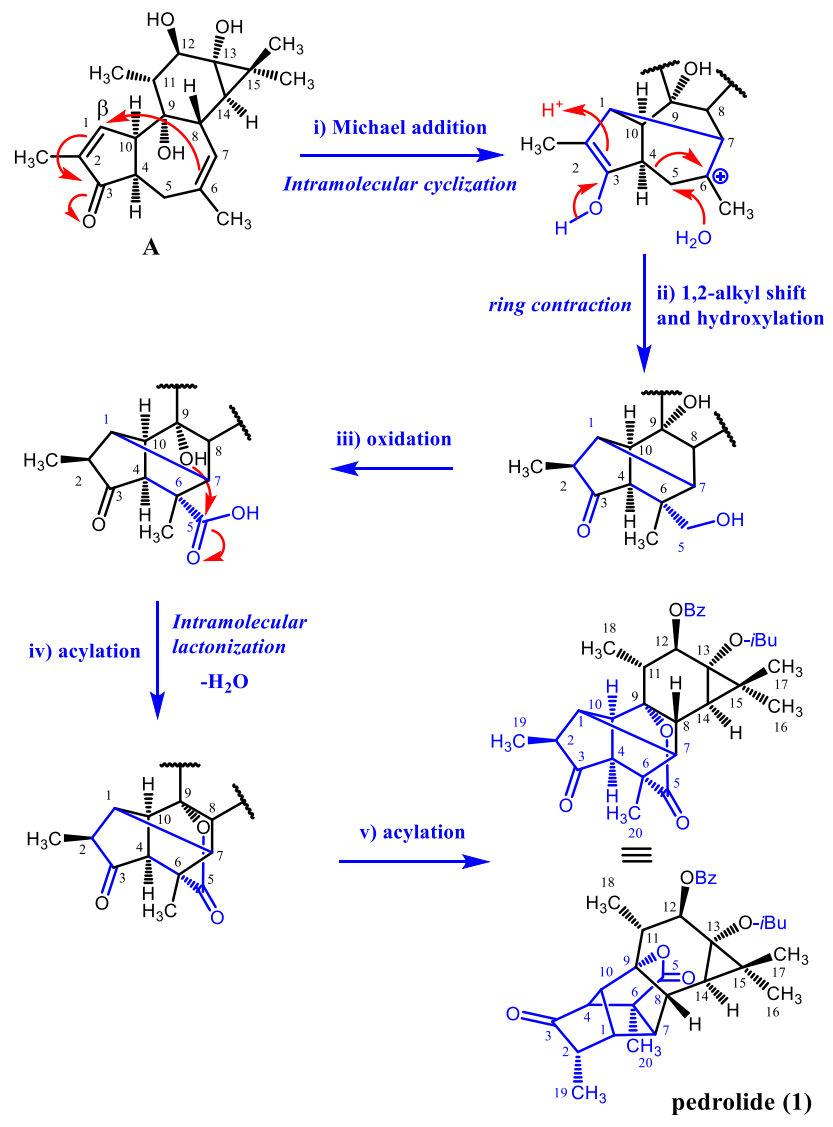

precursor with a tetracyclic diterpene scaffold of the tiglianetype (5/7/6/3 ring system; Scheme $1, A)$, bearing some characteristic features as an $\alpha, \beta$-unsaturated carbonyl at $\mathrm{C}$-3, hydroxyl groups at C-9, C-12, and C-13, and a double bond at C-6. Furthermore, the observed chemical shift for $\mathrm{H}-8\left(\delta_{\mathrm{H}}\right.$ $1.75)$ additionally suggested that this precursor had their rings $\mathrm{A}-\mathrm{B}$ in a cis-fused configuration. ${ }^{1}$

Accordingly, a Michael addition reaction of the double bond at $\mathrm{C}-6$, with the $\beta$-carbon of the $\alpha, \beta$-unsaturated system, leads to intramolecular cyclization, by connecting C-1 with C-7 (Scheme 1, (i)). Next, two simultaneous steps may occur involving a ring contraction, originating the new carboncarbon bond C-4/C-6, via a 1,2-alkyl shift through C-4/C-5 Cbond cleavage, and water attack at C-5 (Scheme 1, (ii)). The oxidation of the resulting hydroxymethyl at C-5 into a carboxylic acid (Scheme 1, (iii)) would favor a nucleophilic attack by the hydroxyl group at C-9, therefore originating the lactone ring (Scheme 1, (iv)).

Alternatively, alkene formation at C-5, epoxidation, epoxide hydrolysis, leading to a vicinal diol, followed by Pinacol rearrangement would generate an aldehyde at C-5, which could be further oxidized to carboxylic acid (Supporting Information, Scheme S1). 
Further acylations at C-12 and C-13 (Scheme 1, (v)) would form pedrolide (1), bearing the new pedrolane-type scaffold.

As it has been proven that orbital interactions have a critical role in the binding of nucleophiles to Michael acceptors, ${ }^{16} a b$ initio calculations were additionally performed. The obtained results support our hypothesis for the first step of proposed biogenetic pathway, only favored when rings $\mathrm{A}-\mathrm{B}$ are in a cisfused configuration (Supporting Information, Figures S21 and S22).

The cytotoxic activity of $\mathbf{1}$ was evaluated in resistant mouse ABCB1-transfected T-lymphoma (L5178Y-MDR) cells and corresponding sensitive subline (L5178Y-PAR), in resistant (Colo320) and sensitive human colon adenocarcinoma cells (Colo205), and in sensitive murine (NIH/3T3) and human (MRC-5) embryonic fibroblast cell lines by the thiazolyl blue bromide (MTT) assay. ${ }^{17,18}$ No relevant cytotoxic effects were found for compound $\mathbf{1}$ in any of the above cell lines, with $\mathrm{IC}_{50}$ values ranging from $73.3 \mu \mathrm{M}$ to more than $100 \mu \mathrm{M}$, (Supporting Information, Table S3).

Multidrug resistance (MDR) to anticancer drugs is the major impediment in the successful treatment of cancer. MDR is frequently associated with the overexpression of $\mathrm{ABC}$ transporter proteins, responsible for removing anticancer drugs from cancer cells, being P-glycoprotein the most implicated. The development of P-gp inhibitors, able to impair the efflux activity of this $\mathrm{ABC}$-transporter, is one of the most promising approaches to overcome MDR in cancer. ${ }^{19}$ The ability of compound 1 to inhibit P-gp efflux was assessed in resistant mouse lymphoma (L5178Y-MDR) and human colon adenocarcinoma (Colo320) cell lines through the rhodamine-123 accumulation assay, at the concentrations of 2 and $20 \mu \mathrm{M}$ and using verapamil as a positive control. Herein, an active compound was defined as having a fluorescence activity ratio $($ FAR $)>1.0$, meaning that the compound was able to impair rhodamine-123 efflux by P-gp. As shown in Figure S13, pedrolide (1) was active in both cell lines (L5178Y-MDR cells, FAR 1.87 and 16.04 at 2 and $20 \mu \mathrm{M}$, respectively; Colo320, FAR 1.64 and 5.36 at 2 and $20 \mu \mathrm{M}$, respectively) and in both cases was found to have a greater activity than verapamil at 20 $\mu \mathrm{M}(\mathrm{FAR}=9.66$ and 4.10 for L5178Y-MDR and Colo320 cells, respectively). As indicated by the absence of significant changes in size (FSC) and granularity (SSC) of the cell population (Supporting Information, Figures S14-S19), toxicity effects could also be excluded in the flow cytometry assay.

Compound $\mathbf{1}$ was also evaluated in combination with the cytotoxic drug doxorubicin, one of the most used anticancer drugs in chemotherapy and a known P-gp substrate. ${ }^{19}$ The extent of interaction between doxorubicin and the compound was calculated by a combination index (CI) as suggested by Chou. The combination index can be estimated using the multiple drug effect equation derived from the median-effect principle of the law of mass-action, providing a quantitative assessment for synergistic $(\mathrm{CI}<1)$, additive $(\mathrm{CI}=1)$, and antagonist $(\mathrm{CI}>1)$ effects. Furthermore, both the potency and shape of the dose-effect curve of each drug alone (and their combination) are also taken into consideration. ${ }^{20,21}$ Thus, any compound able to inhibit P-gp is expected to potentiate cytotoxic effects when coadministered with any given anticancer drug. From the results in Table S4 (Supporting Information) it can be concluded that compound 1 showed a strong synergism $(\mathrm{CI}=0.208)$ with doxorubicin, enhancing its cytotoxicity in resistant L5178Y-MDR cells by more than 6- fold $\left(\mathrm{IC}_{50}=0.396 \mu \mathrm{M}\right.$, against $\mathrm{IC}_{50}=2.49 \mu \mathrm{M}$ of doxorubicin alone).

\section{ASSOCIATED CONTENT}

\section{Supporting Information}

The Supporting Information is available free of charge at https://pubs.acs.org/doi/10.1021/acs.orglett.0c03647.

Material and Methods, IR, MS, and 1D- and 2D-NMR, crystal data/structure refinement, biological activities, and computational details (PDF)

Gaussian16 output files concerning: energy minimization of pedrolide, optical rotation calculations for epimers $4 R$ and $4 S$, and $a b$ initio calculations concerning the energetics of first step of the biogenetic pathway for cis- and trans-fused hypothetical precursor (ZIP)

\section{Accession Codes}

CCDC 1990457 contains the supplementary crystallographic data for this paper. These data can be obtained free of charge via www.ccdc.cam.ac.uk/data_request/cif, or by emailing data_request@ccdc.cam.ac.uk, or by contacting The Cambridge Crystallographic Data Centre, 12 Union Road, Cambridge CB2 1EZ, UK; fax: +44 1223336033.

\section{AUTHOR INFORMATION}

\section{Corresponding Author}

Maria-José U. Ferreira - Research Institute for Medicines (iMed.ULisboa), Faculty of Pharmacy, Universidade de Lisboa, 1649-003 Lisbon, Portugal; 1 orcid.org/00000002-8742-1486; Phone: +351 217946475;

Email: mjuferreira@ff.ulisboa.pt; Fax: +351 217946470

\section{Authors}

Ricardo J. Ferreira - Research Institute for Medicines (iMed.ULisboa), Faculty of Pharmacy, Universidade de Lisboa, 1649-003 Lisbon, Portugal; (1) orcid.org/00000003-2590-8229

Gabriella Spengler - Department of Medical Microbiology and Immunobiology, Faculty of Medicine, University of Szeged, H-6720 Szeged, Hungary

Andreas Orthaber - Department of Chemistry, Ångström Laboratory, Uppsala University, 75120 Uppsala, Sweden; (1) orcid.org/0000-0001-5403-9902

Daniel J. V. A. dos Santos - Research Institute for Medicines (iMed.ULisboa), Faculty of Pharmacy, Universidade de Lisboa, 1649-003 Lisbon, Portugal; LAQV@REQUIMTE/ Department of Chemistry and Biochemistry, Faculty of Sciences, University of Porto, 4169-007 Porto, Portugal

Complete contact information is available at:

https://pubs.acs.org/10.1021/acs.orglett.0c03647

\section{Author Contributions}

All authors have given approval to the final version of the manuscript.

Notes

The authors declare no competing financial interest.

\section{ACKNOWLEDGMENTS}

This project received funding from European Structural \& Investment Funds through the COMPETE Programme and from National Funds through FCT, Portugal (Fundação para a 
Ciência e a Tecnologia), under the Program Grants SAICTPAC/0019/2015 and PTDC/MED-QUI/30591/2017. This study was also supported by the project GINOP-2.3.2-152016-00012 (Hungary) and from Swedish Research Council (Vetenskapsrådet 2017-03727). Ricardo J. Ferreira acknowledges FCT for the $\mathrm{PhD}$ grant SFRH/BD/84285/2012. We also acknowledge Dr. T. Vasconcelos, ISA, Universidade de Lisboa, for plant material identification.

\section{REFERENCES}

(1) Wang, H.-B.; Wang, X.-Y.; Liu, L.-P.; Qin, G.-W.; Kang, T.-G. Tigliane Diterpenoids from the Euphorbiaceae and Thymelaeaceae Families. Chem. Rev. 2015, 115 (9), 2975-3011.

(2) Panizza, B. J.; de Souza, P.; Cooper, A.; Roohullah, A.; Karapetis, C. S.; Lickliter, J. D. Phase I dose-escalation study to determine the safety, tolerability, preliminary efficacy and pharmacokinetics of an intratumoral injection of tigilanol tiglate (EBC-46). EBioMedicine 2019, 50, 433-441.

(3) Sorrento Therapeutics, Inc. A Phase 3 Placebo-Controlled Study to Evaluate the Efficacy and Safety of Intra-Articular Administration of Resiniferatoxin versus Placebo for the Treatment of Moderate to Severe Pain due to Osteoarthritis of the Knee; Clinical trial registration NCT04044742; clinicaltrials.gov, 2020.

(4) Vasas, A.; Hohmann, J. Euphorbia Diterpenes: Isolation, Structure, Biological Activity, and Synthesis (2008-2012). Chem. Rev. 2014, 114 (17), 8579-8612.

(5) Evans, F. J. Naturally Occurring Phorbol Esters; CRC Press, 2018.

(6) Bocklandt, S.; Blumberg, P. M.; Hamer, D. H. Activation of Latent HIV-1 Expression by the Potent Anti-Tumor Promoter 12Deoxyphorbol 13-Phenylacetate. Antiviral Res. 2003, 59 (2), 89-98.

(7) Ferreira, R. J.; Kincses, A.; Gajdács, M.; Spengler, G.; dos Santos, D. J. V. A.; Molnár, J.; Ferreira, M. J. U. Terpenoids from Euphorbia Pedroi as Multidrug-Resistance Reversers. J. Nat. Prod. 2018, 81 (9), 2032-2040.

(8) Ramalhete, C.; Mulhovo, S.; Molnar, J.; Ferreira, M. J. U. Triterpenoids from Momordica Balsamina: Reversal of ABCB1Mediated Multidrug Resistance. Bioorg. Med. Chem. 2016, 24 (21), 5061-5067.

(9) Reis, M. A.; Ahmed, O. B.; Spengler, G.; Molnár, J.; Lage, H.; Ferreira, M. J. U. Jatrophane Diterpenes and Cancer Multidrug Resistance - ABCB1 Efflux Modulation and Selective Cell Death Induction. Phytomedicine 2016, 23 (9), 968-978.

(10) Ferreira, R. J.; Gajdács, M.; Kincses, A.; Spengler, G.; dos Santos, D. J. V. A.; Ferreira, M. J. U. Nitrogen-Containing Naringenin Derivatives for Reversing Multidrug Resistance in Cancer. Bioorg. Med. Chem. 2020, 28 (23), 115798.

(11) Paterna, A.; Khonkarn, R.; Mulhovo, S.; Moreno, A.; Madeira Girio, P.; Baubichon-Cortay, H.; Falson, P.; Ferreira, M. J. U. Monoterpene Indole Alkaloid Azine Derivatives as MDR Reversal Agents. Bioorg. Med. Chem. 2018, 26 (2), 421-434.

(12) Ferreira, R. J.; Baptista, R.; Moreno, A.; Madeira, P. G.; Khonkarn, R.; Baubichon-Cortay, H.; dos Santos, D. J.; Falson, P.; Ferreira, M. J. U. Optimizing the Flavanone Core toward New Selective Nitrogen-Containing Modulators of ABC Transporters. Future Med. Chem. 2018, 10 (7), 725-741.

(13) Aljančić, I. S.; Pesić, M.; Milosavljević, S. M.; Todorović, N. M.; Jadranin, M.; Milosavljević, G.; Povrenović, D.; Banković, J.; Tanić, N.; Marković, I. D.; Ruzdijić, S.; Vajs, V. E.; Tesević, V. V. Isolation and Biological Evaluation of Jatrophane Diterpenoids from Euphorbia Dendroides. J. Nat. Prod. 2011, 74 (7), 1613-1620.

(14) Wang, L.; Yang, J.; Kong, L.-M.; Deng, J.; Xiong, Z.; Huang, J.; Luo, J.; Yan, Y.; Hu, Y.; Li, X.-N.; Li, Y.; Zhao, Y.; Huang, S.-X. Natural and Semisynthetic Tigliane Diterpenoids with New Carbon Skeletons from Euphorbia Dracunculoides as a Wnt Signaling Pathway Inhibitor. Org. Lett. 2017, 19 (14), 3911-3914.

(15) Stephens, P. J.; McCann, D. M.; Devlin, F. J.; Smith, A. B. Determination of the Absolute Configurations of Natural Products via Density Functional Theory Calculations of Optical Rotation,
Electronic Circular Dichroism, and Vibrational Circular Dichroism: The Cytotoxic Sesquiterpene Natural Products Quadrone, Suberosenone, Suberosanone, and Suberosenol A Acetate. J. Nat. Prod. 2006, 69 (7), 1055-1064.

(16) Cardona, W.; Guerra, D.; Restrepo, A. Reactivity of $\delta$ Substituted $\alpha, \beta$-Unsaturated Cyclic Lactones with Antileishmanial Activity. Mol. Simul. 2014, 40 (6), 477-484.

(17) Berridge, M.; Tan, A.; McCoy, K.; Wang, R. The Biochemical and Cellular Basis of Cell Proliferation Assays That Use Tetrazolium Salts. Biochemica 1996, 4, 14-19.

(18) Mosmann, T. Rapid Colorimetric Assay for Cellular Growth and Survival: Application to Proliferation and Cytotoxicity Assays. J. Immunol. Methods 1983, 65 (1-2), 55-63.

(19) Ferreira, R. J.; Ferreira, M. J. U.; dos Santos, D. J. V. A. Reversing Cancer Multidrug Resistance: Insights into the Efflux by ABC Transports from in Silico Studies. WIREs Comput. Mol. Sci. 2015, 5 (1), 27-55.

(20) Chou, T.-C. Drug Combination Studies and Their Synergy Quantification Using the Chou-Talalay Method. Cancer Res. 2010, 70 (2), 440-446.

(21) Chou, T.-C. Theoretical Basis, Experimental Design, and Computerized Simulation of Synergism and Antagonism in Drug Combination Studies. Pharmacol. Rev. 2006, 58 (3), 621-681. 